\title{
Exploration and Analysis on the Differences Between Competitive Wushu and Traditional Wushu
}

\author{
Zhang Xuepeng \\ Graduate school, Chengdu Sport University, Chengdu, Sichuan, China \\ Email, 1020194322@qq.com
}

Key words: Traditional Wushu; Competitive Wushu; Difference

\begin{abstract}
Using literature, expert interviews, comparative analysis, the difference of competitive martial arts and traditional martial arts "as the research object, the difference between the two factors of thinking, in order to harmonious development path of the two. The article thinks: in the functional level, the competitive Wushu competition system by statute, neglect of attack and defense, pay attention to performance implications, but the traditional martial arts highlight simple and practical skills in the field of philosophy; penetration level, competitive Wushu training team or school rely more on living space, the traditional martial arts penetrate in the folk field; in the value orientation in order to obtain the level of Competitive Wushu sports achievements, cultivate highly competitive as the value orientation, the traditional martial arts in the traditional Wushu culture as the value orientation.
\end{abstract}

\section{Introduction}

Wushu is one of the symbols of Chinese culture, which contains the Chinese nation's philosophy and thinking mode. For a long time for the development of Wushu examination identification pattern, seems to be "martial arts" and "traditional Wushu" both mutual promotion and mutual influence of the situation more prominent, especially in the martial arts, development, dissemination and promotion in the context of the time, seems to gradually show their martial arts of traditional martial arts obstacles and interference. Some scholars have pointed out that the "modern competitive Wushu occupy high, seems as China martial arts spokesperson," modernization "is the traditional excuse for slander, belittle and persecution of traditional martial arts, and the" stigma of the "". [1] this means that there are a lot of differences between Competitive Wushu and traditional martial arts, and to some extent, it hinders the development of traditional wushu.

In recent years, although the development of Competitive Wushu increased continuously, heritage of the traditional martial arts in the excavation and protection of everything in good order and well arranged, however, the failure of Competitive Wushu Entering Olympic traditional martial arts gradually lost, their development is not harmonious problem, to arouse the attention of people and thinking, heritage and development is still an important issue of the development of Wushu urgent. So, in the inheritance, development and dissemination of martial arts only in competitive martial arts and traditional martial arts with what identity, what kind of attitude, and what kind of relationship, think and look at their "contextual", seems to be the key to many experts and scholars urgently need to sort out and analysis of the problem. To this end, perhaps more subtle should examine and in-depth analysis of the differences between the two factors, combing both the concept of development, harmonious development of the two ways, perhaps in order to better realize the harmonious development of competitive martial arts and traditional martial arts.

\section{Analysis of the Difference Between Competitive Wushu and Traditional Wushu}

2.1 The Difference of Function Orientation: The Change of Attack and Defense. The orientation of the traditional martial arts function requires not only the technique and principle of practical and effective, also requires practitioners to have strong physique, in order to play a more practical benefit in attack. Master Sun's Art of War," the battle ", taking him by surprise" and "human hair, to the ancestors"; Zhouyi, "Yin and Yang", "loss" and "rigid, static" philosophy by 
many boxing lessons home, become a typical technology of traditional Wushu hammer theory view. Not only that, the traditional martial arts in the long-term practice, rich in warfare and sublimation of these theories, and completed the transformation of the generation, "well ingrained", formed the idea of practical techniques waterhouse.

Table 1 Expert Interview Statistics on the Function of Attack and Defense

\begin{tabular}{|l|l|l|}
\hline & Quantity & Proportion(\%) \\
\hline Competitive Wushu & 2 & 15.40 \\
\hline Traditional Wushu & 11 & 84.60 \\
\hline Total & 13 & 100.00 \\
\hline
\end{tabular}

Although the requirement of Wushu technique and principle are offensive content, however, to a certain extent almost ignored the characteristics of China Wushu practical but it restricts training with high performance speech meaning, so as to get higher scores in the fierce competition. Since 1911 Ma Liang "new Chinese martial arts", to the rapid development of the [2] at the beginning of 1996 "between the martial arts, martial arts in action on the basis of traditional Wushu, to western competitive sports as a reference, change to gold as the ultimate goal of" physical education "project, is the traditional martial arts in the new period of the development of interpretation. Howbeit, in the technical system of Competitive Wushu, can vaguely see a miniature of the traditional martial arts of attack and defense, however, actually showing a beautiful and elegant, contains performance characteristics, showing the charm of artistic gymnastics.

2.2 The Difference of Permeability Field: the Evolution of Living Space. Attached to the traditional martial arts Chinese farming society elements, forming "busy farming, special way to slack boxing", the folk survival space system.

Table 2 Expert Interview Statistics of Traditional Wushu Infiltration Field

\begin{tabular}{|l|l|l|}
\hline & Quantity & Proportion(\%) \\
\hline Nongovernmental & 9 & 69.20 \\
\hline School or Sports Team & 4 & 30.80 \\
\hline Total & 13 & 100.00 \\
\hline
\end{tabular}

The traditional martial arts "was born in the farming civilization, still mainly relies on the folk martial arts community, not only to form stable [3] family and mentoring as the basic unit of human system, has gradually evolved a system of the splendor of the school. The traditional martial arts because it has strong folk heritage and rich folk elements, so as to ensure the survival of the foundation, can be better in the tradition of penetration into folk take it leisurely and unoppressively perspective; because of its distinctive regional characteristics and broad geographical context, in the foundation to enhance the connotation of folk, conceived in the development perspective. Therefore, the development system of the folk horizon and the context of the regional perspective, the traditional martial arts in the living space has obvious folk characteristics.

Competitive Wushu soaked in modern sports competition, formation and development mode in the strict rules of competition restrictions in order to achieve better results for the purpose and to maximize the popularization of Wushu as the goal, determines the temporal and spatial system of Competitive Wushu survival in sports training teams and schools of martial arts.

Table 3 Expert Interview Statistics of Competitive Wushu Infiltration Field

\begin{tabular}{|l|l|l|}
\hline & Quantity & Proportion(\%) \\
\hline Nongovernmental & 3 & 23.10 \\
\hline School or Sports Team & 10 & 76.90 \\
\hline Total & 13 & 100.00 \\
\hline
\end{tabular}

Competitive Wushu with western competitive sports for the development of the image, the pursuit of development idea of "higher, faster and stronger", in the development and popularization of path, forming a permeable space survival mode in sports training teams and schools as the representative of the. Sports training team training high-quality personnel and carry out martial arts wushu successors of humanistic philosophy, the martial arts in the development of technology and theory of limit breakthrough bottleneck; implement the popularization of school Wushu culture and Wushu Wushu talents successors of humanistic idea, make Wushu in developing constantly 
breakthrough popularity and carry forward the dilemma, this decision system of competitive space Wushu in sports training teams and schools of martial arts.

2.3 Differences in Value Orientation: Tradition and the Evolution of the Times. The traditional martial arts in the long-term practice, not only the formation of the bidding function orientation of the enemy, also formed by the extension of the external body technology to the traditional culture Takenori intrinsic value pursuit.

Table 4 Expert Interview Statistics of Traditional Wushu Value Orientation

\begin{tabular}{|l|l|l|}
\hline & Quantity & Proportion(\%) \\
\hline $\begin{array}{l}\text { Value Orientation of Chinese } \\
\text { Traditional Culture }\end{array}$ & 12 & 92.31 \\
\hline $\begin{array}{l}\text { Highly Competitive Value } \\
\text { Orientation }\end{array}$ & 1 & 7.69 \\
\hline Total & 13 & 100.00 \\
\hline
\end{tabular}

The traditional martial arts in the long-term practice, "benevolence, righteousness, propriety, wisdom, faith, loyalty, courage and cultural connotation, become Taking into account both inside and outside lofty spiritual realm". [4] traditional martial arts influenced by the Confucian "benevolence", "formed by the morality of Confucian ethics and" benevolence "as the core, not martial arts before practicing morality, courageous, cruelty and kindness, draw a sword and render help at the sight of injustice" [5] goal; the traditional martial arts by Taoist "harmony of thought", formed a human nature and Taoism the concept of harmony, balance and realm of constant pursuit of me, inside and outside, and ultimately achieve the goal of Yin Yang and the traditional martial arts; Buddhist "mercy for the effects " thought, formed the Buddhist Compassion as the core of the martial repair, and ultimately achieve good one, caring beings and do not take the initiative to attack the enemy target etc.

Owing to the fact that the competitive Wushu is also regulated by the competitive sports, it is bound to follow and reflect the characteristics and principles of competitive sports.

Table 5 Expert Interviews with the Value Orientation of Competitive Wushu

\begin{tabular}{|l|l|l|}
\hline & Quantity & Proportion(\%) \\
\hline $\begin{array}{l}\text { Value Orientation of Chinese } \\
\text { Traditional Culture }\end{array}$ & 6 & 38.50 \\
\hline $\begin{array}{l}\text { Highly Competitive Value } \\
\text { Orientation }\end{array}$ & 7 & 61.50 \\
\hline Total & 13 & 100.00 \\
\hline
\end{tabular}

Competitive sports in the pursuit of maximum digging and play the function of the human body according to the potential to play at the highest level of competition, in order to get the best performance; the pursuit of Competitive Wushu and make full use of strict compliance with the rules of the contest, and gradually improved technical action, to play the game the highest benefit; Competitive Wushu pursuit game without fear keep ahead of the competition, according to the opponent the performance of self adjustment of competitive state of competitive state, to strengthen the higher sense of competition.

\section{Summary}

The difference between Competitive Wushu and traditional Wushu is not formed overnight, but gradually evolves in the context of western competitive sports. The difference of sports function system, living space and the value orientation and the traditional martial arts, martial arts development is not entirely Chinese failures, differences in screening situation of competitive martial arts and traditional martial arts, combined with the current situation of the development of competitive sports, you can faintly see the competitive martial arts is a derivative of the development of traditional martial arts, is the inevitable trend of the development of Wushu in the new during the new period. Make full use of Competitive Wushu competitions as the path of development, and the traditional martial arts in advancing the concept of rational reform, a unique 
way of development and adhere to the folk, perhaps is the equilibrium point of harmonious development of both, and to promote and maintain coordination of competitive martial arts and traditional martial arts development is not only conducive to and carry forward the Chinese martial arts inheritance, more conducive to highlight the charm of the Oriental culture.

\section{References}

[1] Zhang Kun, Zhao Mingyuan. Dilemma and practical ways to return to the traditional martial arts [J]. Journal of Nanjing Sport Institute, 2016,30 (3): 29.

[2] Li long. An analysis of the relationship between traditional Wushu and competitive Wushu [J]. Journal of Beijing Institute of physical education,.2011, 34 (10):138 - 139.

[3] Zhang Changsi, Zhang Changnian. Study on the relationship between Competitive Wushu and traditional Wushu [J]. Journal of Beijing Sport University,.2015 (7): 34.

[4] Peng Nanjing, Zhang Yujia. The ethics of traditional military culture and modern echo of [J]. sports and science, 2017,38 (2): 74.

[5] Zhang Peng, Wang Guozhi. Confucianism thought of martial arts [J]..2015 Journal of Jilin Institute of Physical Education, 31 (4): 92. 